\title{
Risk Factors of Allogenous Bone Graft Collapse in Two- Level Anterior Cervical Discectomy and Fusion
}

\author{
Joon-Bum Woo, ${ }^{1-3}$ Dong-Wuk Son, ${ }^{1-3}$ Su-Hun Lee, ${ }^{1-3}$ Jun-Seok Lee, ${ }^{1-3}$ Sang Weon Lee, ${ }^{1-3}$ Geun Sung Song ${ }^{1-3}$ \\ Department of Neurosurgery, Pusan National University Yangsan Hospital, Yangsan, Korea \\ Research Institute for Convergence of Biomedical Science and Technology, ${ }^{2}$ Pusan National University Yangsan Hospital, Yangsan, Korea \\ Department of Neurosurgery, ${ }^{3}$ Pusan National University School of Medicine, Yangsan, Korea
}

Objective : Anterior cervical discectomy and fusion (ACDF) is commonly used surgical procedure for cervical degenerative disease. Among the various intervertebral spacers, the use of allografts is increasing due to its advantages such as no harvest site complications and low rate of subsidence. Although subsidence is a rare complication, graft collapse is often observed in the followup period. Graft collapse is defined as a significant graft height loss without subsidence, which can lead to clinical deterioration due to foraminal re-stenosis or segmental kyphosis. However, studies about the collapse of allografts are very limited. In this study, we evaluated risk factors associated with graft collapse.

Methods : We retrospectively reviewed 33 patients who underwent two level ACDF with anterior plating using allogenous bone graft from January 2013 to June 2017. Various factors related to cervical sagittal alignment were measured preoperatively (PRE), postoperatively (POST), and last follow-up. The collapse was defined as the ratio of decrement from POST disc height to follow-up disc height. We also defined significant collapses as disc heights that were decreased by $30 \%$ or more after surgery. The intraoperative distraction was defined as the ratio of increment from PRE disc height to POST disc height.

Results : The subsidence rate was $4.5 \%$ and graft collapse rate was $28.8 \%$. The pseudarthrosis rate was $16.7 \%$ and there was no association between pseudarthrosis and graft collapse. Among the collapse-related risk factors, pre-operative segmental angle $(p=0.047)$ and intra-operative distraction $(p=0.003)$ were significantly related to allograft collapse. The cut-off value of intraoperative distraction $\geq 37.3 \%$ was significantly associated with collapse ( $p=0.009$; odds ratio, $4.622 ; 95 \%$ confidence interval, 1.470 14.531). The average time of events were as follows: collapse, $5.8 \pm 5.7$ months; subsidence, $0.99 \pm 0.50$ months; and instrument failure, $9.13 \pm 0.50$ months.

Conclusion : We experienced a higher frequency rate of collapse than subsidence in ACDF using an allograft. Of the various preoperative factors, intra-operative distraction was the most predictable factor of the allograft collapse. This was especially true when the intraoperative distraction was more than $37 \%$, in which case the occurrence of graft collapse increased 4.6 times. We also found that instrument failure occurs only after the allograft collapse.

Key Words : Cervical vertebrae · Spinal fusion · Prosthesis failure · Risk assessment · Allografts.

- Received : January 3, 2019 •Accepted : March 17, 2019

- Address for reprints : Dong Wuk Son

Department of Neurosurgery, Pusan National University Yangsan Hospital, 20 Geumo-ro, Mulgeum-eup, Yangsan 50612, Korea

Tel : +82-55-360-2126, Fax : +82-55-360-2156, E-mail : sondongwuk@gmail.com, ORCID : https://orcid.org/0000-0002-9154-1923

This is an Open Access article distributed under the terms of the Creative Commons Attribution Non-Commercial License (http://creativecommons.org/licenses/by-nc/4.0) which permits unrestricted non-commercial use, distribution, and reproduction in any medium, provided the original work is properly cited. 


\section{INTRODUCTION}

Anterior cervical discectomy and fusion (ACDF) is an effective surgical treatment for radiculopathy or myelopathy due to degenerative cervical spondylosis ${ }^{9}$. In the United States, cervical fusion increased by 89\% between 1993 and 2003, and doubled between 1998 and 2008,19). The use of the iliac crest autogenous bone graft is still a gold standard, but harvest site complications, such as infection, donor site pain, and fracture are frequent $t^{6,10,11,20)}$. To avoid donor site complications, allograft materials are being used as a substitute for an autogenous bone graft. In fact, the use of an autogenous bone graft from 1994 to 2004 decreased from $86 \%$ to $10 \%$, while allograft increased from $14 \%$ to $59 \%{ }^{15)}$.

Allografts have the advantage of no harvest site complications and a low rate of subsidence because of their similar elasticity to the surrounding bone tissue ${ }^{16,25)}$. Although subsidence is a rare complication, graft collapse is often observed in the follow-up period. Graft collapse is defined as a significant graft height loss without subsidence, which can lead to clinical deterioration due to foraminal re-stenosis or segmental kyphosis $^{4)}$.

There have been various comparative studies that focus on the difference between autogenous bone graft and allograft, but studies about the collapse of allografts are very limit$\mathrm{ed}^{3,4,18,24)}$. Suchomel et al. ${ }^{23)}$ reported that multilevel ACDF and smoking were related to allograft collapse. In this study, we evaluated intra-operative and radiological risk factors associated with graft collapse. In addition, we analyzed the influence of collapse on instrument failure or pseudarthrosis.

\section{MATERIALS AND METHODS}

The study protocol was approved by the Institutional Review Board of Pusan National University Yangsan Hospital, which waived the requirement for informed consent due to the retrospective nature of this study. All procedures performed in studies involving human participants were in accordance with the ethical standards of the Institutional Review Board of Pusan National University Yangsan Hospital (IRB No. 05-2019-068).

\section{Patients}

Between January 2010 and June 2017, data from 314 patients who underwent ACDF for cervical spondylosis at a single institution was collected. The inclusion criteria were : 1) ACDF performed by a single surgeon, 2) use of an allograft cage and anterior plating. Exclusion criteria were : 1) stand-alone cage $(\mathrm{n}=137)$, anchor cage, and total disc replacement (TDR) $(n=21), 2) 1$ level ACDF with allograft cage $(n=80), 3)$ follow up within 6 months, and 4) trauma and revision (n=9) (Fig. 1). Thirty-three cases were finally enrolled. Mean age at surgery was $56.2 \pm 11.6$ years. In total, 66 segments (C3-4-5, 4; C4-5-6, 11; C5-6-7, 18) were investigated.

\section{Surgical techniques}

All patients were operated on using the standard SmithRobinson anteromedial left-sided approach ${ }^{22}$. After removal of the intervertebral disc with a careful endplate preparation, a high-speed electric drill and Kerrison punch were used to decompress the nerve roots by removing osteophyte overgrowth on the uncovertebral joint and posterior lips of the vertebral body. We performed bilateral uncinated process resection, even in patients with unilateral symptoms, to eliminate remnant osteophyte regrowth. Adequate decompression was confirmed by the ability of a micro-hook to easily pass through the neural foramen. After decompression was complete, we determined the cage size, screw trajectory, and plate angle using fluoroscopy. An allograft cage (Cornerstone-SR ${ }^{\circledR}$; Medtronic, Memphis, TN, USA) was applied under fluoroscopy. After release of the Caspar distractor, a manual pullout test confirmed the stability of the operation segments. All patients were instructed to wear a soft collar for two months after surgery.

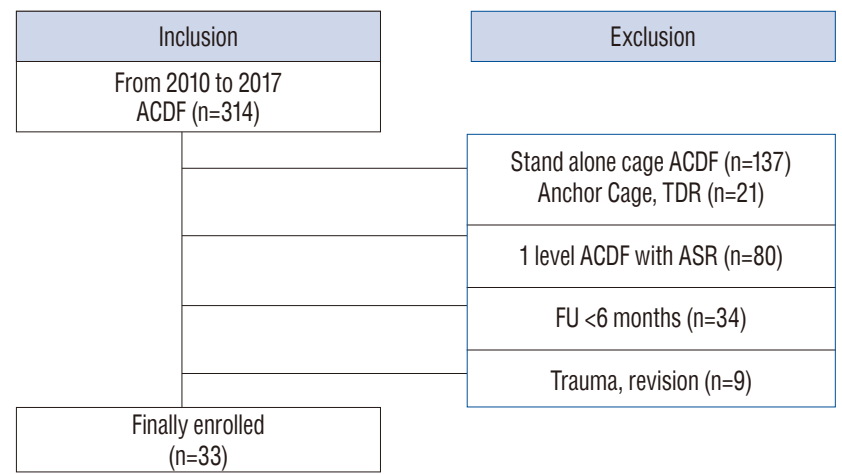

Fig. 1. Flow diagram depicting the patient inclusion process. ACDF : anterior cervical discectomy and fusion, TDR : total disc replacement. 


\section{Radiological parameters}

All radiological assessments were performed by two independent observers that are experienced in spinal diseases. Routine pre-operative radiological work-up consisted of plain radiographs (standing anteroposterior [AP], lateral neutral, lateral flexion, lateral extension, and bilateral oblique views), computed tomography scan, and magnetic resonance imaging. The disc height was defined as the distance from the midpoint of the low endplate of the cephalic vertebra to the closest point of the upper endplate of the caudal vertebra. Plain AP and lateral radiographs on post-operative day 7 (POST) were used to calculate disc height change when patients could stand. The collapse was defined as the ratio of decrement from POST disc height to last follow-up disc height. We also defined significant collapses as disc heights that were decreased by $30 \%$ or more after surgery $y^{4)}$. The following possible risk factors for collapse were considered: pre- and post-operative cervical angle and segmental angle, T1 slope, range of motion, disc height, cage size, plate size, intraoperative distraction, and cage position (Fig. 2). Intraoperative distraction was measured according to the Barsa and Suchomel ${ }^{1)}$ study (Fig. 3). Fusion status was defined as a lack of instability between the vertebral bodies on flexion and extension radiographs or the presence of bony bridging through the intervertebral space or around the cage. Pseudarthrosis was defined as segmental instability with $\geq 2 \mathrm{~mm}$ increase of interspinous distance or $\geq 2^{\circ}$ increase of segmental angle on flexion-extension lateral views at the most recent follow-up ${ }^{25}$. To better understand the contextual relationship between graft collapse and instrument failure, we also measured the time of subsidence, collapse, and instrument failures (screw pull-out or broken).
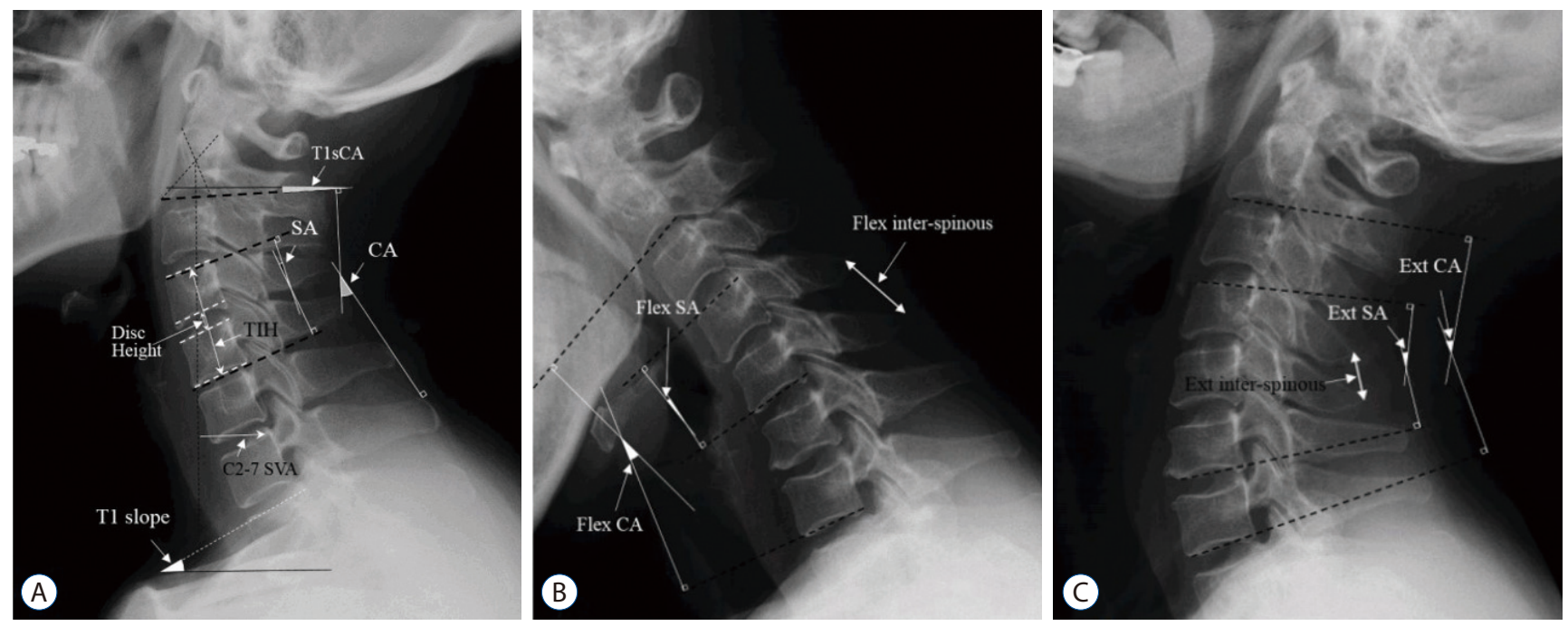

Fig. 2. Measurements of the radiological parameters. $A$ : Neutral lateral image. $B$ : Flexion lateral image. $C$ : Extension lateral image. T1sCA:T1 slope minus $C A$, $S A$ : segmental angle, CA:C2-C7 cervical angle, TIH: total intervertebral height, SVA: sagittal vertical axis, Flex: flexion, Ext : extension.

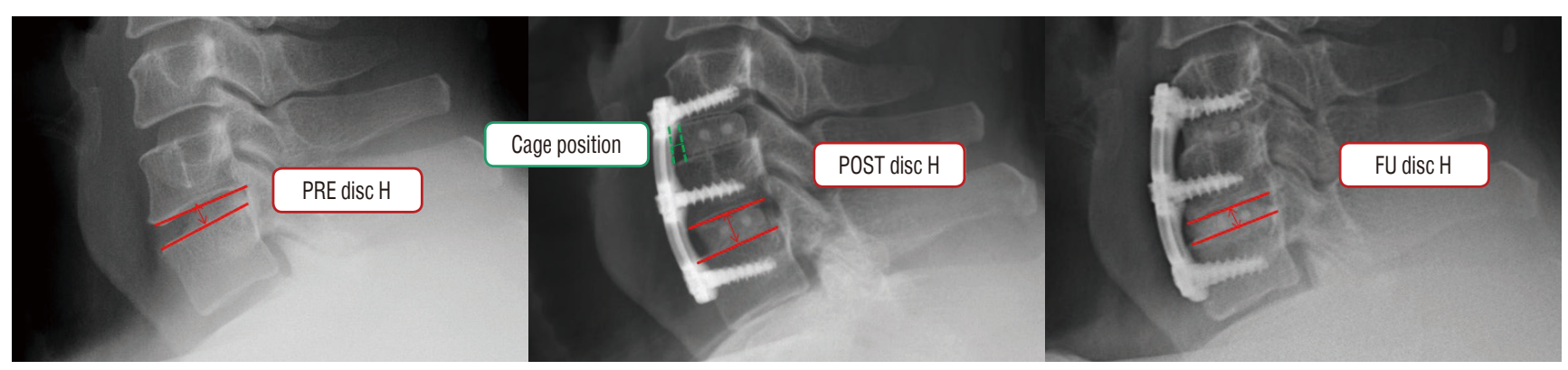

Fig. 3. Definition of Intra-operative distraction and allograft collapse. Intraoperative distraction : [(POST disc height - PRE disc height) / PRE disc height] $\times 100$ (\%). Allograft collapse : [(POST disc height - FU disc height) / POST disc height] $\times 100$ (\%). PRE : pre-operative, H : height, POST : postoperative, FU : last follow-up. 


\section{Statistical analysis}

The Shapiro-Wilk test was used to confirm normal distribution ( $p>0.05)$. Group differences (collapse and non-collapse) in radiologic and clinical outcomes were evaluated using Student's t-tests and Mann-Whitney $U$ tests for parametric and nonparametric continuous variables, respectively. Pearson's correlation analyses were performed, even when only one parameter was normally distributed. A multivariate logistic regression analysis was performed using the backward likelihood ratio method. A receiver-operating characteristic (ROC) analysis was performed and the cut-off value was defined as

Table 1. Patients characteristics

\begin{tabular}{lc}
\hline & Value \\
\hline Demographic data (total 33 patients) & \\
Age (years) & $56.2 \pm 11.6$ \\
Sex (male) & $27 / 6$ \\
Operative level & 66 segments \\
C3-4-5 & 4 \\
C4-5-6 & 11 \\
C5-6-7 & 18 \\
DM & $9 / 33$ patients \\
Smoking & $13 / 33$ patients \\
\hline
\end{tabular}

DM : diabetes mellitus

Table 2. Incidence of subsidence and collapse

\begin{tabular}{lc}
\hline & Value \\
\hline Incidence of subsidence and collapse & \\
Subsidence & $3 / 66$ segments $(4.5 \%)$ \\
Collapse & $19 / 66$ segments $(28.8 \%)$ \\
Pseudarthrosis & $11 / 66$ segments (16.7\%) \\
\hline
\end{tabular}

the point corresponding to the maximum sum of the sensitivity and specificity. A $p<0.05$ was considered statistically significant. All analyses were performed using SPSS version 21 for Windows (SPSS Inc., Chicago, IL, USA).

\section{RESULTS}

\section{Patient characteristics}

The average age of the 33 patients was 56 years and there were more men than women. The total operative level was 66 segments (Table 1). As a result, subsidence was seen at three segments (4.5\%), collapse at 19 segments (28.8\%), and pseudarthrosis at 11 segments (16.7\%) (Table 2). Diabetes mellitus was associated with pseudarthrosis, but not with collapse or instrument failure. Smoking was not associated with subsidence, collapse, or instrument failure (Table 3).

\section{Risk factors of collapse}

Collapse-related risk factors were assessed, and multivariate regression analysis revealed that the pre-operative segmental angle $(p=0.047)$ and intra-operative distraction $(p=0.003)$ were independent risk factors of collapse (Table 4). To evaluate how well intra-operative distraction could predict collapse, we performed ROC analysis. The area under curve was 0.689 , and it reached statistical significance $(p=0.017$ ) (Fig. 4). The cut-off value of intra-operative distraction was $37.3 \%$ (sensitivity, 0.681 ; specificity, 0.684). Using this value, we converted intraoperative distraction into a bifurcated variable (distraction $<37.3 \%$, distraction $\geq 37.3 \%$ ), and performed logistic regression analysis, which revealed that this cut-off value was significantly associated with collapse $(p=0.009$; odds ratio, 4.622;

Table 3. DM and smoking associated with pseudarthrosis, subsidence, collapse or instrument failure

\begin{tabular}{|c|c|c|c|c|c|c|}
\hline & DM & Control & $p$-value & Smoking & Control & $p$-value \\
\hline Subsidence & 2 & 1 & 0.178 & 2 & 1 & 0.552 \\
\hline Control & 16 & 47 & & 23 & 40 & \\
\hline Instrument failure & 2 & 3 & 0.608 & 3 & 2 & 0.359 \\
\hline Control & 16 & 45 & & 22 & 39 & \\
\hline Collapse & 2 & 17 & 0.052 & 10 & 9 & 0.116 \\
\hline Control & 16 & 31 & & 15 & 32 & \\
\hline Pseudarthrosis & 6 & 5 & $0.026^{*}$ & 4 & 7 & 0.910 \\
\hline Control & 12 & 43 & & 21 & 34 & \\
\hline
\end{tabular}

*Indicated $p<0.05$. DM : diabetes mellitus 
Table 4. Risk factors of collapse

\begin{tabular}{|c|c|c|c|c|c|c|}
\hline & \multicolumn{3}{|c|}{ Non adjusted } & \multicolumn{3}{|c|}{ Adjusted } \\
\hline & B & OR & $p$-value & B & OR & $p$-value \\
\hline Age & -0.094 & 0.911 & 0.080 & -0.56 & 0.946 & 0.090 \\
\hline Sex & 3.363 & 28.869 & 0.061 & & & \\
\hline Upper (ref)/lower & -0.882 & 0.414 & 0.357 & & & \\
\hline PRE disc $\mathrm{H}$ & 0.149 & 1.160 & 0.734 & & & \\
\hline PRE CA & -0.117 & 0.890 & 0.280 & & & \\
\hline PRE SA & 0.303 & 1.354 & 0.064 & 0.092 & 1.096 & $0.047^{*}$ \\
\hline PRE SVA & -0.015 & 0.985 & 0.765 & & & \\
\hline PRE T1S & 0.029 & 1.029 & 0.747 & & & \\
\hline PRE ROM & 0.079 & 1.082 & 0.071 & 0.050 & 1.051 & 0.073 \\
\hline Cage size & -1.370 & 0.254 & 0.120 & & & \\
\hline Plate size & 0.306 & 1.160 & 1.358 & & & \\
\hline Intra-OP distraction & 1.231 & 3.426 & 0.012 & 0.809 & 2.245 & $0.003^{*}$ \\
\hline Cage position & 0.164 & 1.178 & 0.619 & & & \\
\hline Intra-OP distraction $>37.3$ & 1.531 & 4.622 & 0.009 & & & \\
\hline
\end{tabular}

*Indicated $p<0.05$. B : unstandardized coefficients, OR : odds ratio, ref : reference, PRE : pre-operative, H : height, CA : C2-7 Cobb's angle, SA : segmental angle, SVA : C2-7 sagittal vertical axis, T1s : T1 slope, ROM : range of motion, Intra-OP : intraoperative

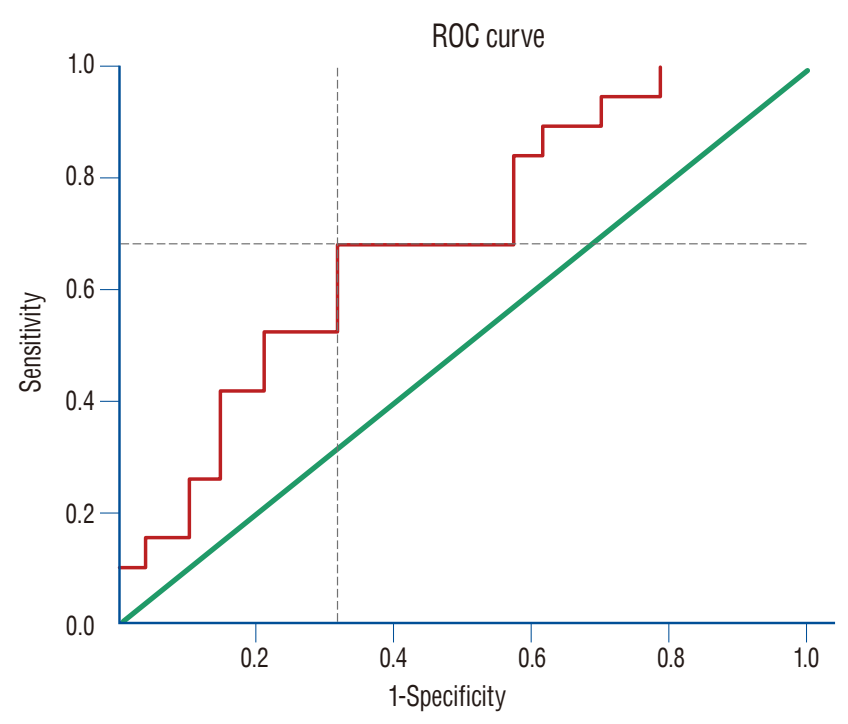

Fig. 4. A ROC analysis for evaluate the intraoperative distraction. ROC : receiver operating characteristic.

95\% confidence interval, 1.470-14.531) (Table 4).

\section{The relationship between graft collapse, instru- ment failure, and pseudarthrosis}

Instrument failure occurred in five cases, among which screw broken was four cases and screw pull out was one case.
When assessing the contextual relationship between instrument failure and graft collapse, four cases experienced collapse first, followed by instrument failure. Only one case experienced collapse and instrument failure at the same time. The average time of events were as follows : collapse, $5.8 \pm 5.7$ months; subsidence, $0.99 \pm 0.50$ months; and instrument failure, $9.13 \pm 0.50$ months (Table 5). In addition, we also evaluated the relationship between graft collapse, instrument failure and pseudarthrosis. As described above, instrument failure and collapse were significantly related $(p=0.001)$. However, there was no relationship between pseudarthrosis and collapse ( $p \geq 0.999)$, and instrument failure $(p=0.580)$ (Table 6).

\section{DISCUSSION}

ACDF is an effective treatment for cervical myelopathy and cervical degenerative disease. In particular, the intervertebral spacer has an important role to achieve cervical fusion as well as maintain cervical stability, disc space, and neural foramen space. Although an autogenous bone graft is the gold standard as an intervertebral spacer, the use of substitutes is increasing due to the autogenous bone graft donor site complica- 
Table 5. The relationship between graft collapse, instrument failure, and pseudarthrosis

\begin{tabular}{lc}
\hline & Value \\
\hline Instrument failure type & \\
Screw broken & 4 screws/4 patients \\
Screw pull-out & 1 screw/1 patient \\
Contextual influence between graft & \\
collapse and instrument failure & 4 \\
Collapse $\rightarrow$ instrument failure & 1 \\
Instrument failure and collapse & 0 \\
Instrument failure $\rightarrow$ collapse & \\
Time of event (months) & $5.8 \pm 5.7(1.73-21.27)$ \\
Collapse & $0.99 \pm 0.50(0.73-1.57)$ \\
Subsidence & $9.13 \pm 0.50(2.3-15.6)$ \\
Instrument failure & \\
\hline
\end{tabular}

tions $^{6,10,11,15,20)}$. Among the substitutes, there have been many comparative studies conducted about performing an allograft with an autogenous bone graft. Suchomel et al. ${ }^{23)}$ focused on the difference of fusion rate as well as fusion periods of an allograft and autograft. The bone fusion ratio of an allograft and autograft after surgery was $25 \%$ vs. $64.9 \%$, and $63 \%$ vs. $89 \%$ at 3 and 6 months, respectively. There was no statistically significant difference in fusion rate after 1 year ${ }^{23)}$. Recently, Tuchman et al. ${ }^{24)}$ have shown that allografts have similar effectiveness to autografts through systematic review. In that respect, the use of an autogenous bone graft from 1994 to 2004 decreased from $86 \%$ to $10 \%$, while use of an allograft increased from $14 \%$ to $59 \%{ }^{15)}$.

During the overview of the course of an allogenous bone graft fusion, we found the absorption phase at 3 months postoperative (Fig. 5). The absorption indicates the disappearance

Table 6. The relationship between graft collapse, instrument failure, and pseudarthrosis

\begin{tabular}{|c|c|c|c|c|c|}
\hline & Collapse & Control & Pseudarthrosis & Control & $p$-value \\
\hline Instrument failure & 5 & 0 & & & 0.0013 \\
\hline Control & 14 & 47 & & & \\
\hline Collapse & & & 3 & 16 & $>0.999$ \\
\hline Control & & & 8 & 39 & \\
\hline Instrument failure & & & 0 & 5 & 0.580 \\
\hline Control & & & 11 & 50 & \\
\hline
\end{tabular}

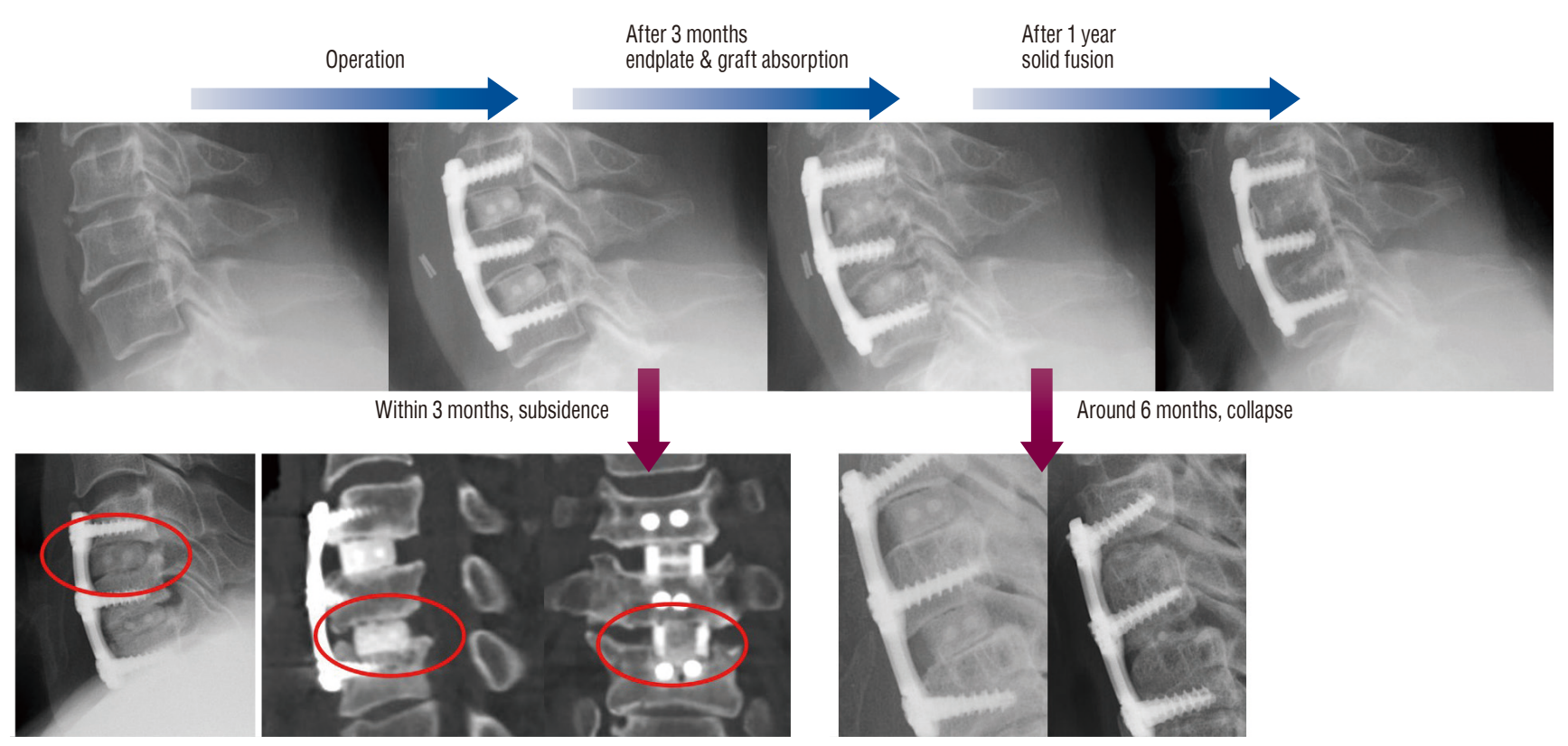

Fig. 5. A course of allogenous bone graft fusion. Red circles indicate a subsidence. 
of the clear border between the endplate and the graft, and also the shrinkage of the bone graft shape in an X-ray image. In many cases, this absorption phase does not progress to significant height loss. However, 28.8\% of segments showed significant height loss at 6 months post-operative. Brown et al. ${ }^{4}$ was the first to define this phenomenon as collapse. The collapse rate is reported as between $4.3 \%$ to $30 \%{ }^{23,26)}$. Among the collapsed segments, five segments underwent instrument failure around 9 months as the collapse proceeded. There was no case in which instrument failure occurred first, followed by collapse. Even in the occurrence of collapse or instrument failure, most cases proceeded to solid fusion at 1-year post-operative. We also found that subsidence occurred at 1-month post-operative, which is before absorption.

Although similar, subsidence and collapse are different concepts. They are similar because they both result in a loss of disc height, loss of segmental lordosis, and a decrement of neural foramen dimension after the ACDF. However, the difference between subsidence and collapse is the involvement of the endplate. In particular, the occurrence of subsidence or collapse depended on the type of graft materials. Due to the fact that the polyether-ether-ketone (PEEK) or titanium cage has more elasticity than the surrounding bone, subsidence occurs more frequently than collapse. In contrast, the autogenous or allogenous bone graft has similar or less elasticity than the surrounding bone, therefore collapse is more frequent than subsidence. Many studies have already reported the risk factors of subsidence in PEEK/titanium cage, such as cage type $^{2,8,21)}$, cage location ${ }^{17)}$, intra-operative distraction ${ }^{7)}$, end-plate preparation ${ }^{14)}$, and cervical sagittal alignment ${ }^{12,13)}$. However, currently there are very limited studies about the absorption of an allograft.

In our study, we identified intra-operative distraction as a risk factor for collapse. An intra-operative distraction is an essential procedure to obtain adequate surgical visual field and decompression during surgery. However, since over-distraction increases the risk of collapse, it is necessary to know the appropriate threshold value. In this regard, this study suggested the cut-off value as $37 \%$ of distraction; this value would be useful in cage selection during surgery.

This study has several limitations. First, as this study is a retrospective study of a small sample size, we cannot perform the subgroup analysis according to pre-operative dish height. Second, the concept of intra-operative distraction has inher- ent limitations; it is overestimated in patients with low preoperative disc height and is underestimated in patients with high pre-operative disc height. To solve this problem, subgroup analysis according to the disc height is needed, but because of the small sample size of this study, it was not performed. Third, some patients had a short follow up period that prevented fusion from being assessed. Fourth, due to the limited coverage of Korea National Insurance, we could not select another cage type such as PEEK or a titanium cage with anterior plating. Therefore, it was not possible to conduct a comparative study of an allogenous bone graft with other type cages.

\section{CONCLUSION}

We experienced a higher frequency rate of collapse than subsidence in ACDF using an allograft. Of the various preoperative factors, intra-operative distraction was the most predictable factor of the allograft collapse. This was especially true when the intraoperative distraction was more than $37 \%$, in which case the occurrence of graft collapse increased 4.6 times. We also found that instrument failure occurs only after the allograft collapse.

\section{CONFLICTS OF INTEREST}

No potential conflict of interest relevant to this article was reported.

\section{INFORMED CONSENT}

This type of study does not require informed consent.

\section{AUTHOR CONTRIBUTIONS}

\author{
Conceptualization : JBW, DWS \\ Data curation : JBW, SHL, JSL \\ Formal analysis : JBW, SHL, JSL \\ Funding acquisition : DWS \\ Methodology : JBW, DWS, SHL, JSL, SWL, GSS
}


Project administration : JBW

Visualization : JBW, SHL

Writing - original draft : JBW

Writing - review \& editing : JBW, DWS, SHL, JSL, SWL, GSS

\section{- Acknowledgements}

This work was supported by the National Research Foundation of Korea (NRF) grant funded by the Korea government (MSIT) (No. NRF-2018R1C1B5045855).

\section{References}

1. Barsa P, Suchomel P : Factors affecting sagittal malalignment due to cage subsidence in standalone cage assisted anterior cervical fusion. Eur Spine J 16 : 1395-1400, 2007

2. Bartels RH, Donk RD, Feuth $T$ : Subsidence of stand-alone cervical carbon fiber cages. Neurosurgery 58 : 502-508, 2006

3. Bishop RC, Moore KA, Hadley MN : Anterior cervical interbody fusion using autogeneic and allogeneic bone graft substrate: a prospective comparative analysis. J Neurosurg 85 : 206-210, 1996

4. Brown MD, Malinin TI, Davis PB : A roentgenographic evaluation of frozen allografts versus autografts in anterior cervical spine fusions. Clin Orthop Relat Res : 231-236, 1976

5. Cowan JA Jr, Dimick JB, Wainess R, Upchurch GR Jr, Chandler WF, La Marca $\mathrm{F}$ : Changes in the utilization of spinal fusion in the United States. Neurosurgery 59 : 15-20, 2006

6. Fernyhough JC, Schimandle JJ, Weigel MC, Edwards CC, Levine AM : Chronic donor site pain complicating bone graft harvesting from the posterior iliac crest for spinal fusion. Spine (Phila Pa 1976) 17 : 14741480, 1992

7. Francke El, Demetropoulos CK, Agabegi SS, Truumees E, Herkowitz HN : Distractive force relative to initial graft compression in an in vivo anterior cervical discectomy and fusion model. Spine (Phila Pa 1976) 35 : 526-530, 2010

8. Gercek E, Arlet V, Delisle J, Marchesi D : Subsidence of stand-alone cervical cages in anterior interbody fusion: warning. Eur Spine J 12 : 513516, 2003

9. Gore DR, Sepic SB : Anterior cervical fusion for degenerated or protruded discs. A review of one hundred forty-six patients. Spine (Phila Pa 1976) 9 : 667-671, 1984

10. Hu R, Hearn T, Yang J : Bone graft harvest site as a determinant of iliac crest strength. Clin Orthop Relat Res : 252-256, 1995

11. Kurz LT, Garfin SR, Booth RE Jr : Harvesting autogenous iliac bone grafts. A review of complications and techniques. Spine (Phila Pa 1976) 14 : 1324-1331, 1989
12. Lee SH, Lee JS, Sung SK, Son DW, Lee SW, Song GS : A lower T1 slope as a predictor of subsidence in anterior cervical discectomy and fusion with stand-alone cages. J Korean Neurosurg Soc 60 : 567-576, 2017

13. Lee SH, Son DW, Lee JS, Kim DH, Sung SK, Lee SW, et al. : Differences in cervical sagittal alignment changes in patients undergoing laminoplasty and anterior cervical discectomy and fusion. Neurospine $15: 91-100$, 2018

14. Lim $T H$, Kwon H, Jeon CH, Kim JG, Sokolowski M, Natarajan R, et al. : Effect of endplate conditions and bone mineral density on the compressive strength of the graft-endplate interface in anterior cervical spine fusion. Spine (Phila Pa 1976) 26 : 951-956, 2001

15. McGuire KJ, Harrast J, Herkowitz H, Weinstein JN : Geographic variation in the surgical treatment of degenerative cervical disc disease: American Board of Orthopedic Surgery Quality Improvement Initiative; part II candidates. Spine (Phila Pa 1976) 37 : 57-66, 2012

16. Miller LE, Block JE : Safety and effectiveness of bone allografts in anterior cervical discectomy and fusion surgery. Spine (Phila Pa 1976) 36 : 20452050, 2011

17. Park JY, Choi KY, Moon BJ, Hur H, Jang JW, Lee JK : Subsidence after single-level anterior cervical fusion with a stand-alone cage. J Clin Neurosci 33 : 83-88, 2016

18. Pelker RR, Friedlaender GE, Markham TC : Biomechanical properties of bone allografts. Clin Orthop Relat Res : 54-57, 1983

19. Rajaee SS, Bae HW, Kanim LE, Delamarter RB : Spinal fusion in the United States: analysis of trends from 1998 to 2008. Spine (Phila Pa 1976) $37: 67-76,2012$

20. Sasso RC, LeHuec JC, Shaffrey C, Spine Interbody Research Group : Iliac crest bone graft donor site pain after anterior lumbar interbody fusion: a prospective patient satisfaction outcome assessment. J Spinal Disord Tech 18 Suppl : S77-S81, 2005

21. Schmieder $K$, Wolzik-Grossmann M, Pechlivanis I, Engelhardt M, Scholz $M$, Harders $A$ : Subsidence of the wing titanium cage after anterior cervical interbody fusion: 2-year follow-up study. J Neurosurg Spine 4 : 447-453, 2006

22. Smith GW, Robinson RA : The treatment of certain cervical-spine disorders by anterior removal of the intervertebral disc and interbody fusion.

J Bone Joint Surg Am 40-A : 607-624, 1958

23. Suchomel P, Barsa P, Buchvald P, Svobodnik A, Vanickova E : Autologous versus allogenic bone grafts in instrumented anterior cervical discectomy and fusion: a prospective study with respect to bone union pattern. Eur Spine J 13 : 510-515, 2004

24. Tuchman A, Brodke DS, Youssef JA, Meisel HJ, Dettori JR, Park JB, et al. : Autograft versus allograft for cervical spinal fusion: a systematic review. Global Spine J 7 : 59-70, 2017

25. Yang JJ, Yu CH, Chang BS, Yeom JS, Lee JH, Lee CK : Subsidence and nonunion after anterior cervical interbody fusion using a stand-alone polyetheretherketone (PEEK) cage. Clin Orthop Surg 3 : 16-23, 2011

26. Zdeblick TA, Ducker TB : The use of freeze-dried allograft bone for anterior cervical fusions. Spine (Phila Pa 1976) 16 : 726-729, 1991 